\title{
Introducing Neo-Riemannian Theory in AP Curriculum through Liszt's Liebestraum No. 3
}

\author{
Nikita Mamedov
}

\begin{abstract}
Advanced Placement (AP) Music Theory, a high school course that covers analytical and performative aspects of music, is offered to students who are interested in obtaining college-level credits. Score analysis is one of the major components that the AP students are required to master. Theory instructors commonly teach music analysis through available resources on traditional harmony, focusing on branches of music theory, such as Roman numeral analysis, form, counterpoint, and four-part writing. This research will propose how the Neo-Riemannian theory and its three primary transformations can complement the knowledge that students obtain throughout the course. This paper employs Liszt's Liebestraum No. 3 to show analytical examples and the function such examples serve in music theory pedagogy.
\end{abstract}

Index Terms-AP music theory, Liszt, music education, music theory pedagogy, Neo-Riemannian analysis.

\section{INTRODUCTION}

Music education is an essential component of $\mathrm{K}-12$ and collegiate level curriculums, presenting students of all levels with opportunities to enhance their knowledge in the fields of music appreciation, history, theory, performance, technology, and pedagogy. As a subject of study, music presents one with academic and social benefits. By taking music courses, students are able to develop critical thinking capabilities, interact with their peers, and generate scholarly connections with other subjects through reading, listening, and writing. Additionally, students learn how to formulate and frame own understanding of the subject content [1]. Majority of schools offer music courses as electives, allowing students to learn and expand in the topics that they show interest and fascination in. A solid music program typically consists of analysis courses in theory, as well as performance courses, where students can participate in the school's jazz band and choir [2]. However, music is likewise an important constituent of Advanced Placement curriculum that must be taken seriously by those who are looking to earn college credits, obtain scholarships (both internal and extramural), and increase their chances of college admission. The type of music education that is offered in high schools has a direct correlation with how students will perform academically in their music classes at university level, which is particularly important for those, who chose to continue their musical studies professionally [3].

The high school AP Music Theory course is designed for two semesters, particularly targeting students in 11th and 12th

Manuscript received January 9, 2019; revised June 28, 2019.

Nikita Mamedov is with North America International School, Shanghai, 201199, China (e-mail: mamedov.n@north-america.cn). grades. In this course, students develop musical capabilities, which allow them to become proficient in their analytical and compositional skills [4]. Music theory studies how music is made and how it works. Music theory allows one to analyze compositions by different composers from various stylistic periods by applying a specific set of musical vocabulary and terminology to define the occurring musical phenomena. In this course, students learn the rudiments of conducting and sight-singing, as well as the fundamentals of music notation, various types of musical chords, chord structures, harmonic analysis, and form, all embodied into the study of correlation between the melody and the harmony [5]. AP Music Theory course is equivalent to the primary musicianship courses offered at the university level.

\section{TEACHING AP MUSIC THEORY}

Presently, there are multiple sources that can be utilized by instructors when teaching AP Music Theory depending on the knowledge and the proficiency level of the students. One of the primary academic resources to teach this subject is Baron's AP Music Theory textbook by Scoggin [6]. The book presents complex topics in an accessible way, providing detailed step-by-step instructions on how to fully prepare for the AP Music Theory exam. Complementary material includes Concise Introduction to Tonal Harmony by Burstein and Straus, Tonal Harmony with an Introduction to Twentieth-Century Music by Kostka and Payne, and A New Approach to Sight Singing by Berkowitz, and while not specifically designed to teach AP topics, these textbooks are very comprehensive when it comes to explaining the central principles of music theory, which students are required to master, and are likewise commonly employed at the university levels by instructors teaching classes in introductory music theory and musicianship [7]-[9]. The strong aspect of Concise Introduction to Tonal Harmony is its ability to explain music theory from a scientific approach and to define various theoretical concepts by emphasizing on rules and guidelines of how to solve various theoretical problems without incorporating the assumptions or personal thoughts of the authors. Similarly, the theory textbook by Kostka and Payne attempts to simplify the theoretical topics so that students can understand the theory at the most fundamental level, as authors focus on vocabulary and terminology to define theoretical phenomena that occurs in music analysis. Likewise, alternative pedagogical resources are available through the AP Central website, such as publications in the field of music theory on College Board and The Journal of Music Theory Pedagogy [10]. 


\section{PuRPOSE OF THE STUDY}

The proper knowledge of keys and scales is essential for one to master in music theory to work with musical analysis and to operate with various theoretical approaches when dissecting compositions [11]. A set of keys in music is a system that generates a network of major and minor scales. A scale is a pattern of notes in a particular order (that can be both ascending and descending). The Baron's AP Music Theory textbook, for instance, dedicates a complete chapter for these concepts. Without the proper knowledge of keys and scales, students will struggle when applying music theory to understand compositions and will not be able to fully grasp the necessity of harmonic analysis. Furthermore, this may lead to struggles with advanced theoretical topics should the students pursue higher-level theory, such as, for example, Schenkerian analysis.

There is a total of twenty-four keys in Western classical music, which include twelve major and twelve minor scales, and students are expected to know the respective key signature of each key [12]. While multiple approaches exist in music theory pedagogy to teach key signatures of such scales, all of them lead to students having to learn the exact number of sharps and flats in each key. This can be explained through the implementation of the circle of fifths that generates a geometric representation of keys and key signatures [13], [14] A circle of fifth with the twenty-four different keys is shown in Fig. 1 [15].

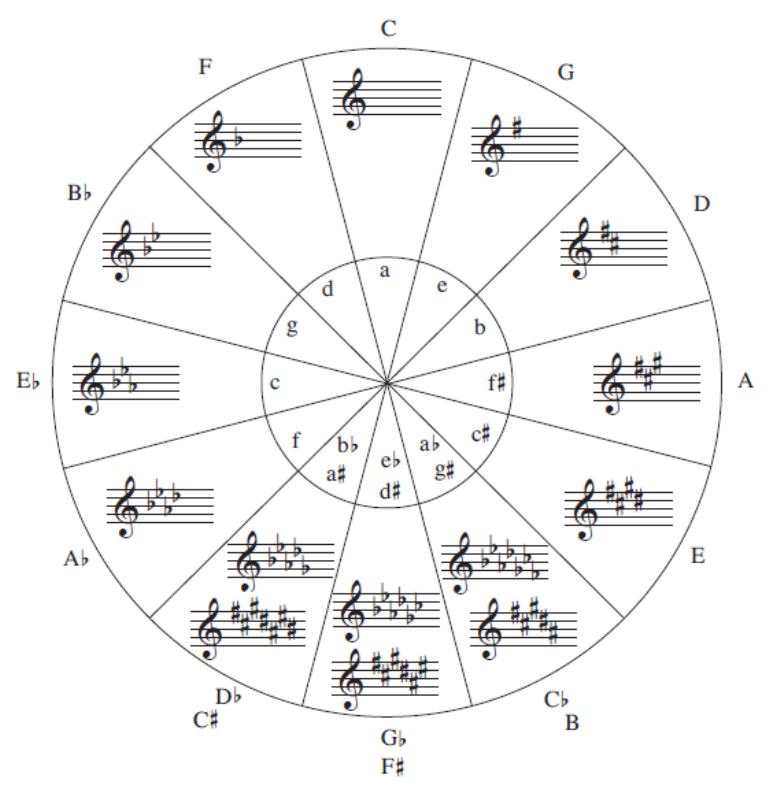

Fig. 1. Circle of fifths.

The familiarity with the keys and scales, however, is not nearly enough for full understanding of how music functions, as students need to apply such knowledge in their musical analysis of works by different composers, which can be done, for example, through the ability to recognize parallel keys and relative keys, as well as the musical relations that both keys encompass between multiple compositions. Two parallel keys are a set of major and minor keys with identical tonic and different key signatures, such as $\mathrm{C}$ major and $\mathrm{C}$ minor. Both keys share an identical tonic. The key of $\mathrm{C}$ major contains no sharps or flats, while the key of $\mathrm{C}$ minor contains three flats. There is a total of twelve sets of parallel keys. On the contrary, two relative keys are a set of major and minor keys with identical key signature and different tonic, such as D major and B minor. Both keys contain two sharps, yet have different tonics.

The application of parallel and relative keys is significant in music theory from compositional perspective. This can be seen in both books of Bach's Well-Tempered Clavier, where the twenty-four preludes are composed chromatically in every major and minor key. Each major key is followed by its parallel (or enharmonically-equivalent parallel) minor key. This can likewise be seen through the analysis of Chopin's Op. 28 - a set of twenty-four preludes, each composed in a unique key, where each set of two keys are relative. Therefore, the first and the second preludes are in the keys of $\mathrm{C}$ major and $\mathrm{A}$ minor, the third and the fourth preludes are in the keys of $G$ major and E minor, and et cetera [16].

However, the idea of parallel and relative keys is not new to music theorists and has been employed before the modern integration of harmonic analysis into the AP curriculum. These principles are the building blocks of Neo-Riemannian theory (as well as the theories of dualism, developed by Oettingen) [17]. This research proposes the integration of all fundamental concepts of Neo-Riemannian theory and their applied functions to enhance the learning process of students in the AP music theory course. First, such integration will allow students to rapidly identify and recognize key signatures in scales and keys, as well as vice versa. Second, students will gain an insight into the compositional approaches of late-Romantic composers, which become evident through Neo-Riemannian applications [18]. Third, the knowledge of Neo-Riemannian theory that students obtain can be used as a stepping stone and as a transition into other branches of the AP curriculum such as the concepts of retrograde and inversions in music [19]. Fourth, the principles of Neo-Riemannian theory can be used to further clarify the major and minor triads and their function in various compositions.

It is important to note that the goal of this research is not to show how Neo-Riemannian analysis can replace traditional harmonic analysis, but how the Neo-Riemannian analysis can complement what is already taught in AP Music Theory courses.

\section{NEO-RIEMANNIAN THEORY}

There have been multiple attempts to incorporate Neo-Riemannian model into early theory studies and Mason's master's thesis, titled Essential Neo-Riemannian Theory for Today's Musicians, mentions a few of such sources [20]. Some of the notable works are written by Roig-Francolí (2002), Engebretsen \& Broman (2007), and Straus (2016) [21]-[23]. The unique aspect of Neo-Riemannian theory is that it allows one to view music from the perspective of harmonic zones without any association with tonality or pitch centricity. Such theory presents an insight in how two or more keys are related and how they function in a particular composition. Neo-Riemannian theory can likewise explain high amount of chromaticism and define the multiple levels of voice leading. There are three primary conversions in 
Neo-Riemannian theory, which include the P-transformation, the R-transformation, and the L-transformation. The P-transformation, also labeled as "parallel", occurs between a major and a minor key with identical tonic and contrasting key signature. From Neo-Riemannian perspective, the third scale degree of the triad generates a motion of a semitone. The R-transformation, also labeled as "relative", occurs between a major and a minor key with contrasting tonic and identical key signature. From Neo-Riemannian perspective, the fifth scale degree ascends by a whole tone in major-to-minor transformation and the first scale degree descends by a whole tone in minor-to-major transformation. The AP theory curriculum covers these transformations, albeit using terminology from perspective of tonal harmonic theory, something that does not always work with the analysis of lateand post-Romantic composers, as seen in music of Liszt, Wagner, and Mahler. Furthermore, none of the AP sources provide any information on the L-transformation, which can fundamentally be explained from the perspective of Neo-Riemannian theory and not harmonic theory. In the L-transformation, the leading tone descends by a semitone in major-to-minor conversion and the fifth scale degree ascends by a semitone in a minor-to-major conversion. The three sets of fundamental notions that serve as the nucleus of Neo-Riemannian ideology are shown in Fig. 2.

\begin{tabular}{|c|c|c|c|}
\hline P-transformation (major to minor): & $C-E-G$ & $\rightarrow$ & $\mathrm{C}-\mathrm{E} b-\mathrm{G}$ \\
\hline (identical tonic and different key signature) & C major & $\rightarrow$ & $\mathrm{C}$ minor \\
\hline P-transformation (minor to major): & $\mathrm{C}-\mathrm{E} b-\mathrm{G}$ & $\rightarrow$ & $C-E^{\natural}-G$ \\
\hline (identical tonic and different key signature) & $\mathrm{C}$ minor & $\rightarrow$ & $\mathrm{C}$ major \\
\hline R-transformation (major to minor): & $C-E-G$ & $\rightarrow$ & $C-E-A$ \\
\hline (identical key signature and different tonic) & C major & $\rightarrow$ & A minor \\
\hline R-transformation (minor to major): & $A-C-E$ & $\rightarrow$ & $\mathrm{G}-\mathrm{C}-\mathrm{E}$ \\
\hline (identical key signature and different tonic) & A minor & $\rightarrow$ & $\mathrm{C}$ major \\
\hline L-transformation (major to minor): & $\mathrm{C}-\mathrm{E}-\mathrm{G}$ & $\rightarrow$ & $B-E-G$ \\
\hline (different key signature and different tonic) & $\mathrm{C}$ major & $\rightarrow$ & E minor \\
\hline L-transformation (minor to major): & $E-G-B$ & $\rightarrow$ & $\mathrm{E}-\mathrm{G}-\mathrm{C}$ \\
\hline (different key signature and different tonic) & E minor & $\rightarrow$ & $\mathrm{C}$ major \\
\hline
\end{tabular}

Fig. 2. Primary Neo-Riemannian transformations.

Both approaches have their positive attributes. The traditional harmonic theory tells the students what to know when it comes to scales and keys. Students are able to comprehend the structure of all scales, as well as define each scale's makeup through the perspective of melodic intervals and each scale's interconnection through key signatures. The Neo-Riemannian theory explains how key regions function from triadic perspective, which is essential to understand, as one of the primary guiding questions of music theory is how the music that we listen to, sing, and play works, and how it functions. Therefore, while the traditional approach to teaching keys tells us "what" happens, the Neo-Riemannian methodology complements with "why" it happens.

\section{APPLICATION TO AP CURRICULUM}

An example of how Neo-Riemannian theory can be used to complement traditional Roman numeral analysis can be seen in Liszt's Liebestraum No. 3. Liszt was a prominent Romantic composer from Hungary, known for protruding reforms in piano music and revolutionary modifications in compositional approach both from melodic and harmonic outlooks. His extravagant pianism and virtuosic manners did not go unnoticed and his innovations in performance practice, as well as various stylistic developments can be traced in the set of three Liebesträume, based on poetry of Uhland and Freiligrath. Completed and published in 1850, Liebestraum No. 3 in $\mathrm{Ab}$ major is one of the most popular works by Liszt, known among music enthusiasts just as well as among professional musicians. The piece consists of three sections with the musical climax occurring in $\mathrm{mm}$. $37-41$, as shown in Fig. 3 [24].

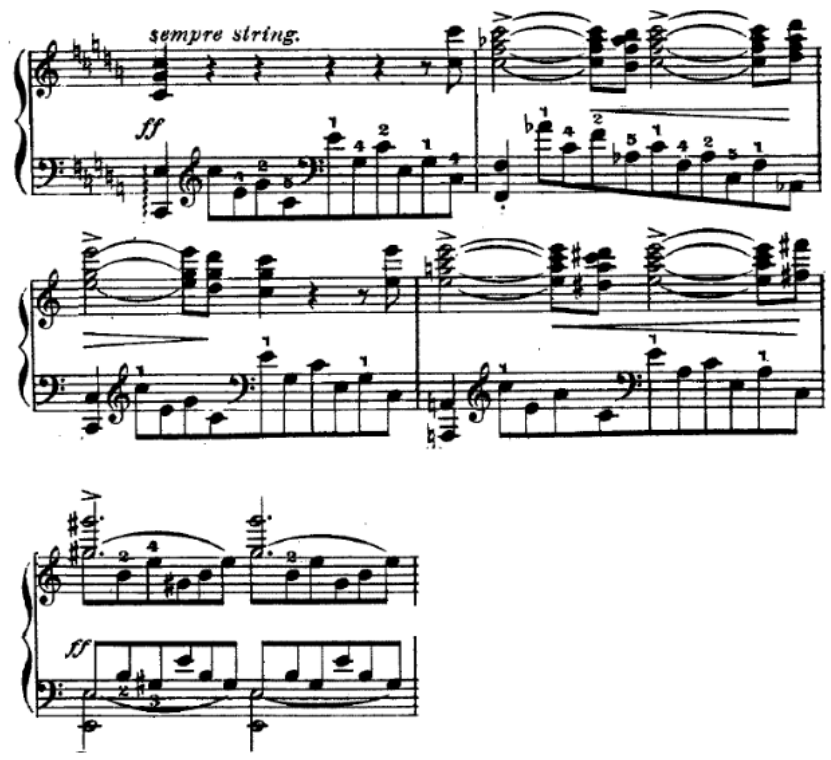

Fig. 3. Liszt, Liebestraum No. 3, mm. 37-41.

Traditional Roman numeral analysis shows that there exists a total of five harmonic regions as the progression advances from $\mathrm{C}$ major to $\mathrm{E}$ major. In this excerpt, each measure can be thought of as a separate harmonic space. Therefore,

m. $37=\mathrm{C}$ major

m. $38=\mathrm{F}$ minor

m. $39=\mathrm{C}$ major

m. $40=$ A minor

m. $41=$ E major

The first and the third regions, defined by the key of $\mathrm{C}$ major, are identical and share the same key signature as the fourth region - A minor. While the keys of $\mathrm{C}$ major and $\mathrm{A}$ minor have no sharps or flats, the key of $\mathrm{F}$ minor has four flats and the key of E major has four sharps. This information is essential from analytical standpoint, yet it does not present us with any insight into Liszt's compositional process and how these keys are linked harmonically. A careful Neo-Riemannian analysis will prove that three of the four transformations generate a P-L-R cycle, or in other words - a combination of three unique transformations, as shown in Fig. 4. It takes a P-transformation, followed by an L-transformation, followed by an R-transformation to 
advance from $\mathrm{C}$ major to $\mathrm{F}$ minor.

P-transformation of $\mathrm{C}$ major $=\mathrm{C}$ minor

L-transformation of $\mathrm{C}$ minor $=\mathrm{A} b$ major

R-transformation of $\mathrm{A} b$ major $=\mathrm{F}$ minor

Similar cycle exists between $\mathrm{F}$ minor and $\mathrm{C}$ major, as well as A minor and E major.

P-transformation of $\mathrm{F}$ minor $=\mathrm{F}$ major

L-transformation of $\mathrm{F}$ major $=\mathrm{A}$ minor

R-transformation of A minor $=\mathrm{C}$ major

P-transformation of A minor $=\mathrm{A}$ major

L-transformation of A major $=\mathrm{C} \#$ minor

$\mathrm{R}$-transformation of $\mathrm{C} \#$ minor $=\mathrm{E}$ major

While it is essential to point out the harmonic regions and be able to explain what they mean, it is likewise vital to see how these key areas connect, which defines the zenith of Liszt's compositional process, especially during the buildup towards the musical apogee, seen in the left hand's arpeggiation that is overshadowed by the right hand's primary melody.

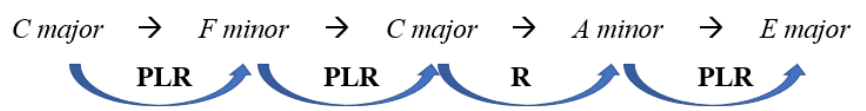

Fig. 4. Neo-Riemannian view of mm. 37-41 in Liszt's Liebestraum No. 3.
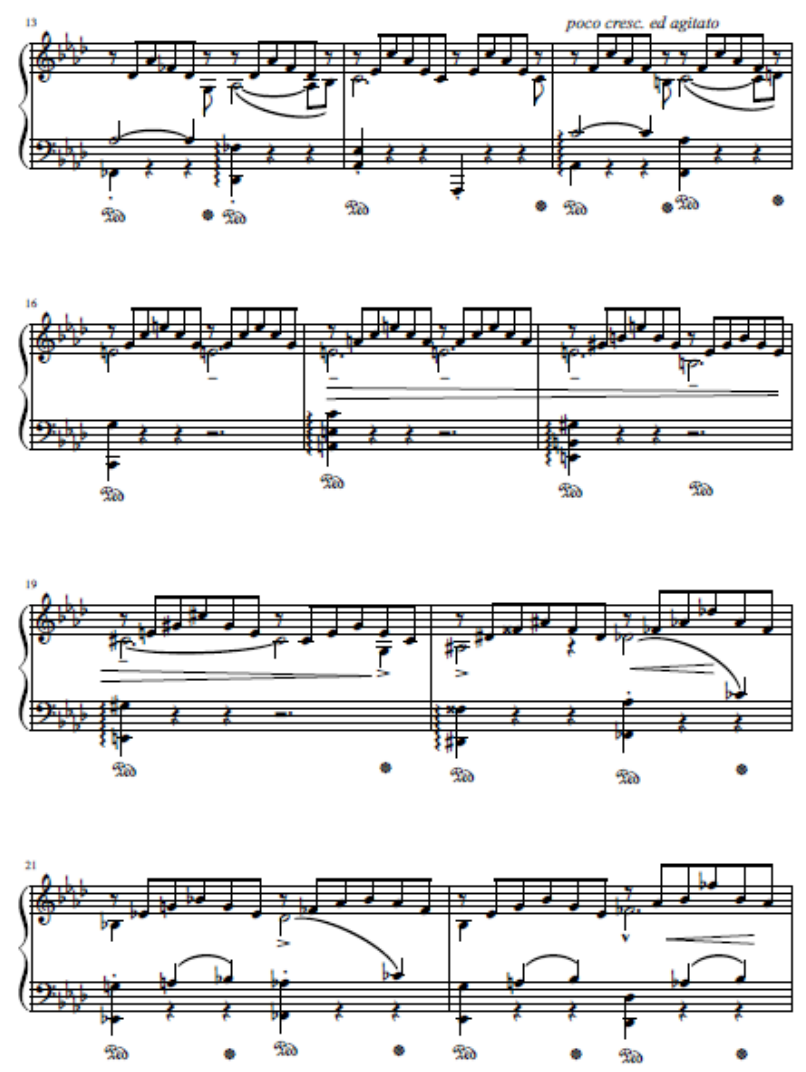

Fig. 5. Liszt, Liebestraum No. 3, mm. 13-22.

This is a sufficient amount of information to understand the structure and the construction of Liszt's harmonies. This likewise allows students to see the correlation between the multiple harmonic regions and what musical meaning such regions occupy in the bigger scope of the composition as a whole. The exclusivity of Liebestraum and the careful compositional choices of Liszt allow one to take this analysis a step further, as seen in mm. 13-22. Fig. 5 shows the original music right before the initialization of cadenza and the end of the A-section, while Fig. 6 presents the Neo-Riemannian analysis of this excerpt. As in the previous example, the right hand's accompaniment is of most importance here, generating a series of uniquely chosen harmonies. As evident from Neo-Riemannian interpretation, the opening seven harmonies are interconnected by an interplay of $R$ and PLR transformations. Both of these combinations are likewise seen in mm. 37-41. The final six key areas are harmonically fascinating through their complexity.

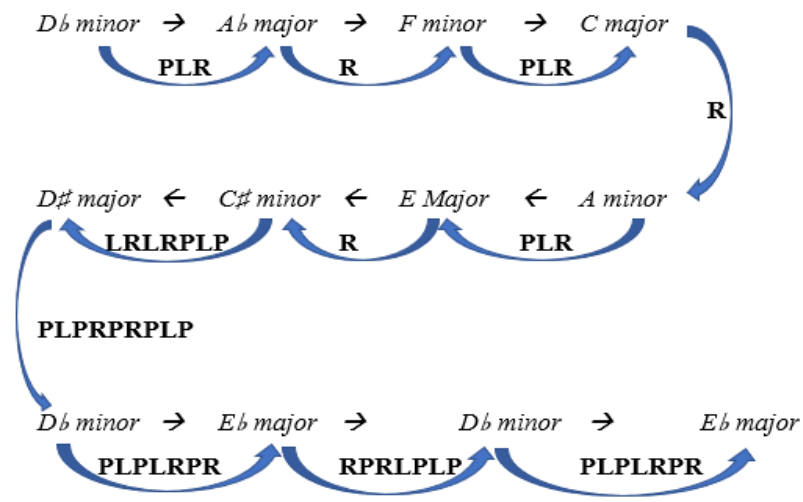

Fig. 6. Neo-Riemannian view of mm. 13-22 in Liszt's Liebestraum No. 3.

In a classroom setting, an instructor may assign multi-step Neo-Riemannian transformation problems to students as extra credit to be completed for homework to enhance their critical thinking capabilities. Finally, it is important to note that a multi-step transformation between $\mathrm{D} \#$ major and $\mathrm{D} b$ minor contains a total of nine permutations, paving its way into another concept of the AP curriculum - the retrograde. The PLPRPRPLP cycle is identical if read in reverse order. Such phenomena can only be noticed through Neo-Riemannian theory, which is important to understand and trace compositional patterns in Liszt's music. It is highly unlikely that Liszt intended to compose this excerpt based on the theoretical pattern described above and no such evidence exists, yet the analytical investigation of "how" the music is composed presents a tangible insight into the study of music theory beyond the traditional harmonic analysis.

\section{CONCLUSION}

The Neo-Riemannian theory can be utilized with success in the AP curriculum by supplementing the analytical information not evident through pedagogy based on traditional study of harmony. By conducting simple Neo-Riemannian exercises in the AP Music Theory course, students will be more proficient with the keys and their respective key signatures. Neo-Riemannian theory allows students to see how the voice leading in each triad functions and allows for transformations from one key region into another. Neo-Riemannian theory likewise allows students to understand how the music of post-Chopin era works. Harmonic analysis reveals the differences, but the explanation behind the compositional contrast is located purely in the core of Neo-Riemannian theories. The Baron's AP Music Theory textbook, for instance, mentions Wagner's melodic contributions to the art of composition, seen in his use of leitmotifs (associating a musical excerpt or a motive with a 
character). The textbook goes as far as to present musical examples from Die Walküre, yet the composer's developments in harmonic musical language are just as significant and can be incorporated into the curriculum through Neo-Riemannian approach. For future research, other late-Romantic and post-Romantic works can be analyzed from Neo-Riemannian perspective and implemented as examples to define and explain the concepts of PLR transformations to students in the AP Music Theory class. Finally, while the knowledge of theoretical concepts is vital to successfully complete the course and obtain a high score on the AP Music Theory exam, one must realize how to combine such concepts in comprehension of the music literature, something that Neo-Riemannian theory does, as seen from the above analysis of Liszt's Liebestraum No. 3.

The Neo-Riemannian theory is a beneficial supplement to the lessons in harmony in today's music theory classes. The Neo-Riemannian approach presents instructors with a variety of opportunities to bridge the study of harmony from common practice period with the study of triadic chromaticism. The purpose of music theory is to keep up with the constant stylistic and musical evolution based on composers' artistic production and the implementation of Neo-Riemannian concepts will allow us to do so when dissecting the works of innovative composers, such as Liszt.

\section{CONFLICT OF INTEREST}

The author declares no conflict of interest.

\section{AUTHOR CONTRIBUTIONS}

Nikita Mamedov conducted the research, analyzed the data, and wrote the paper.

\section{REFERENCES}

[1] J. Wiggins. (January 2007). Authentic practice and process in music teacher education. Music Educators Journal. [Online]. 93(1). pp. 36-42. Available: https://www.jstor.org/stable/4101537

[2] R. J. Dammers. (2010). A case study of the creation of a technology-based music course. Bulletin of the Council for Research in Music Education. [Online]. 186(1). pp. 55-65. Available: https://www.jstor.org/stable/41110434

[3] M. Darby, "Challenges to student success in an introductory music theory I course," Ph.D. dissertation, College of Education, Walden University, Minneapolis, MN, 2018.

[4] The College Board. (2018). AP Music Theory: Course Overview. [Online]. https://apstudent.collegeboard.org/apcourse/ap-music-theory

[5] The College Board. (2018). AP Music Theory Course Description. [Online]. Available: http://media.collegeboard.com/digitalServices/pdf/ap/ap-music-theor y-course-description.pdf

[6] N. F. Scoggin, Barron's AP Music Theory, Hauppauge, NY: Barron's Educational Series Inc., 2018, pp. 1-675.
[7] L. P. Burstein and J. N. Straus, Concise Introduction to Tonal Harmony, New York, NY: W. W. Norton \& Company Ltd., 2016, pp. 1-370.

[8] S. Kostka and D. Payne, Tonal Harmony, New York, NY: McGraw-Hill Education, 2017, pp. 1-704.

[9] S. Berkowitz, A New Approach to Sight Singing, New York, NY: W. W. Norton \& Company Ltd., 2017, pp. 1-410.

[10] M. T. Lively, "Teaching materials and strategies for the AP music theory exam," Music Educators Journal, vol. 104, no. 1, pp. 47-54, September 2017

[11] J. Clough, J. Conley, and C. Boge, Scales, Intervals, Keys, Triads, Rhythm and Meter, 3rd ed. New York, NY: W. W. Norton \& Company Ltd., 1999, pp. 84-90.

[12] E. Henry, Fundamentals of Music. Rudiments, Musicianship, and Composition, 5th ed. Upper Saddle River, NJ: Prentice Hall Inc., 2008, pp. 44-46.

[13] D. Tymoczko, A Geometry of Music: Harmony and Couterpoint in the Extended Common Practice, New York, NY: Oxford University Press, 2011, pp. 19-22.

[14] D. Tymoczko, "The geometry of musical chords," Science, vol. 313, no. 1, pp. 72-74, July 2007.

[15] B. Benward and M. Saker, Music in Theory and Practice, $8^{\text {th }}$ ed. New York, NY: McGraw-Hill Inc., 2009, pp. 27-47.

[16] I. Poniatowska, Fryderyk Chopin: The Man and His Music, Warsaw, Poland: Multico Oficyna Wydawnicza, 2010, pp. 145-152.

[17] R. Münnich, "On the evolution of riemannian harmonic theory and its relation to oettingen and stumpf," Indiana Theory Review, vol. 16, no. 1, pp. 200-222, 1995.

[18] A. Popoff, Towards a Categorical Approach of Transformational Music Theory, 2014, pp. 14-16.

[19] V. V. Johnson, "The relevance of music theory concepts and skills as perceived by in-service music educators," Vision of Research in Music Education, vol. 25, no. 1, pp. 1-22, December 2014.

[20] L. F. Mason, "Essential Neo-Riemannian theory for today's musician," M.M. thesis, Dept. of Music, The University of Tennessee, Knoxville, Tennessee, 2013.

[21] M. Roig-Francoli, Tonal Harmony, New York, NY: McGraw-Hill Education, 2002, pp. 314-321.

[22] N. Engebretsen and P. F. Broman, "Transformational theory in the undergraduate curriculum - A case for teaching the Neo-Riemannian approach," Music Theory Pedagogy, vol. 21, no. 1, September 2007.

[23] J. N. Straus, Introduction to Post-Tonal Theory, 4th ed. New York, NY: W. W. Norton \& Company Ltd., 2016, pp. 158-165.

[24] F. Liszt, Liebesträume, Lepzig, Germany: Kistner, 1903, pp. 222-223.

Copyright $@ 2019$ by the authors. This is an open access article distributed under the Creative Commons Attribution License which permits unrestricted use, distribution, and reproduction in any medium, provided the original work is properly cited (CC BY 4.0).

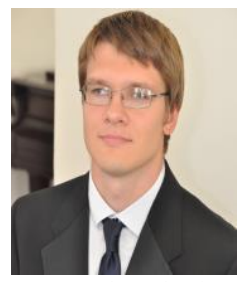

Nikita Mamedov is from St. Petersburg, Russia. He holds a bachelor of music degree in piano and music theory \& composition from Rider University, a master of music degree in piano pedagogy \& performance from Rider University, and a Ph.D. in music with concentration in music theory and minor in musicology from Louisiana State University.

He worked as an instructor of record at Louisiana State University between 2015 and 2018. Currently, he is a music teacher at the North America International School in Shanghai, China. His research interests include music theory pedagogy, music and literature, and music and mathematics.

Dr. Mamedov received Bridges Organization travel awards for the past three years (2016 - 2018). He also held Louisiana Dean's travel award in 2017 and Louisiana CMDA travel grant in 2016. 